\title{
ATCA - thermal management study for the ATLAS phase II upgrades
}

\section{Claudio Bortolin ${ }^{1}$}

CERN European Laboratory for Particle Physics

Geneva CH-1211, Switzerland

E-mail: claudio.bortolinecern.ch

\section{Damian Dyngosz ${ }^{\mathrm{a}}$, Michal Kalinowski ${ }^{\mathrm{b}}$, Piotr Koziol ${ }^{\mathrm{c}}$, Jan Walerianczyk ${ }^{\mathrm{d}}$}

Cracow University of Technology, Mechanical Department

Cracow 31-864, Poland

E-mail: adamian.dyngosz@cern.ch; ${ }^{b}$ michal.kalinowski@cern.ch;

cpiotr.jan.koziolacern.ch; dwalerianczyk.jan@gmail.com

\section{Julian Mendez ${ }^{\mathrm{e}}$, Lukasz Zwalinski ${ }^{\mathrm{f}}$}

CERN European Laboratory for Particle Physics

Geneva CH-1211, Switzerland

E-mail: ${ }^{e}$ julian.mendez@cern.ch; flukasz.zwalinski@cern.ch

The AdvancedTCA (ATCA) telecom industry standard has been selected as the hardware platform for the "Phase-II Upgrade" of ATLAS at the Large Hadron Collider (LHC) at CERN. In November 2014 a project dedicated to the study of the impact of the ATCA integration in the actual counting rooms was launched analysing the impact on the cooling infrastructures. A spare rack equipped with two ATCA shelves, high power dissipating load blades, temperature and air velocity sensors were installed in a lab. Vertical and horizontal cooling performance were checked and some critical aspects identified.

Topical Workshop on Electronics for Particle Physics 11 - 14 September 2017

Santa Cruz, California

\section{${ }^{1}$ Speaker}




\section{Introduction}

The Electronics groups at CERN has selected [1] the AdvancedTCA (ATCA) telecom industry standard as the hardware platform for the "Phase-II Upgrade" of the back-end electronics systems of the ATLAS experiment at the Large Hadron Collider (LHC) at CERN [2]. This hardware is going to replace part of the existing electronic equipment, which is mainly based on the VME standard and has insufficient cooling capability for the upgrade.

For historical reasons at ATLAS experiment, the electronics equipment in the so-called LHC racks, are cooled by a closed vertical recirculating airflow system, from bottom to top. All such racks are equipped with a main ventilation unit housing a smoke detection system and ambient temperature sensors. This existing airflow system is not compatible with the default telecom industry ATCA standard based on horizontal airflow. Additionally, ATCA boards will dissipate significantly more power than the existing equipment and the cooling performance of the existing rack infrastructure may become an issue.

During 2014, the Electronics Systems for Experiments (PH-ESE) group at CERN launched an evaluation project which focused on the electronics infrastructure, with the objective of defining a common set of specifications across the LHC experiments [2]. However, the integration of these new crates, known as ATCA shelves, into the existing rack infrastructure of the ATLAS experiment must be assessed separately, especially the impact on the room cooling and noise. For this reason, the ATLAS technical coordination launched in November 2014 a project dedicated to the study of the cooling capabilities of the upgrade infrastructure.

An ATCA shelve can house up to 14 blades. The maximum power dissipation foreseen is $450 \mathrm{~W}$ per blade. Thus the total power dissipated by one shelf, including the required internal fan power, can exceed $7 \mathrm{~kW}$. For the cooling integration study, a spare rack was equipped with nearly 200 temperature sensors and two ATCA shelves. These were equipped with 28 load blades in total, 14 of them limited to $350 \mathrm{~W} / \mathrm{blade}$, while the rest were limited to $600 \mathrm{~W} / \mathrm{blade}$. The average power dissipation from both blade types enabled the target specification of $450 \mathrm{~W} /$ blade to be verified.

Different shelf layouts (vertical and horizontal airflow), power loads, number of heat exchangers, fan layouts, failure modes and low water temperature configurations were tested and compared with simulations carried out by an ATCA shelf manufacturer. Various operational scenarios were tested in order to assess the impact on the counting room environment (i.e.: air conditioning, noise, etc.).

The project aimed also to provide guidelines to the electronic developer regarding the cooling limits in terms of horizontal and vertical airflow distribution.

\section{System description}

\section{1 - Rack, heat exchangers and cooling door}

Since the beginning of the LHC operations in 2008, around 250 52U LHC standard racks have operated in the ATLAS counting rooms, located in the service cavern (USA15). Since 2015 a spare rack has been equipped with numerous temperature (T) sensors (PT100 4 wires [3]) and air flow sensors. These, along with ATCA blade embedded T sensors, were connected to a data 
acquisition system to study the thermal performance of the system at full power dissipation $(14 \mathrm{~kW})$.

a)

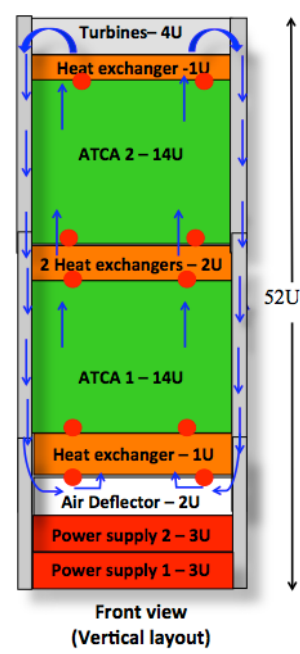

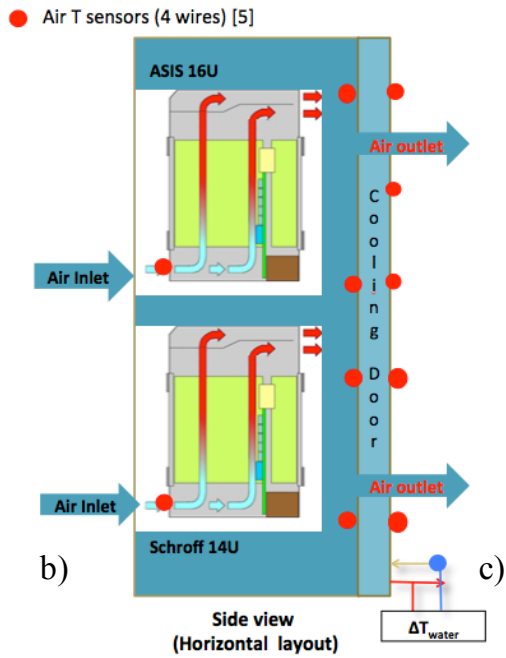

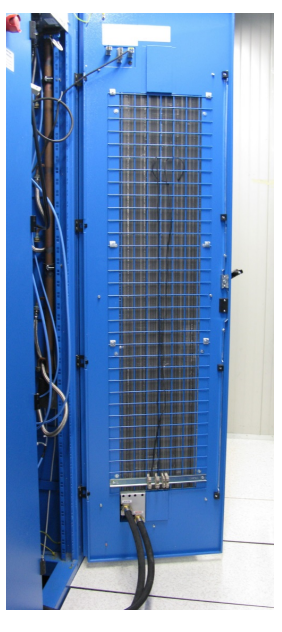

Figure 1: a) vertical, b) horizontal layouts and their air paths represented with arrows, c) cooling door used for horizontal air flow tests

The vertical cooling tests were carried out using the following equipment and infrastructure (Fig. 1a): 2 power supplies for the shelves, 1 air deflector that changes the airflow direction, driving the air up through the ATCA shelves, 4 air/water heat exchangers and the tangential rack turbine unit installed at the top of the rack to drive the air down through the rack side panels to the air deflector. Each heat exchanger has a surface exchange area of $630 \times 443 \mathrm{~mm}$ and could provide potentially up to $3.8 \mathrm{~kW}$ of thermal capacity. However, because the shelves are smaller than the heat exchangers, the real exchange surface was only $56 \%$ of the total capacity.

With the horizontal configuration (Fig. 1b), the front to back air flow is released to the room through a cooling door, connected to the water circuit (Fig. 1c). The total power removed by the water circuit was calculated for both the vertical and door heat exchangers so that their suitability for the ATLAS counting room could be evaluated.

\section{2 - Shelves and load blades}

Two ATCA custom shelves (14U) with open bottom to top air flow were provided by ASIS in order to test the vertical configuration. They were equipped with 4 push-pull fan trays ( 3 on the top and 1 on the bottom) to optimize the airflow pressure. A Schroff shelf (14U) and an ASIS (16U) were used for the horizontal tests. The fan trays were the same as those used in the vertical configuration. In both test configurations the shelves were equipped with 28 load boards installed vertically, 14 designed and built by ASIS and 14 by Comtel. Their maximum working temperature was $50^{\circ} \mathrm{C}$.

The ASIS load blades [4] can provide the air and surface temperature measurements at the inlet and outlet of the blades (Fig. 2a). They were equipped with $10 \mathrm{~T}$ sensors, 2 on the bottom and 8 on the top of the blades surface. They were not provided with Rear Transition Modules (RTM). The Comtel load blades [5] had eight heating zones based on Surface-Mount Device (SMD) resistors (Fig. 2b). Next to each resistor, a temperature sensor is installed. They can dissipate up to $300 \mathrm{~W}$ in the front board and $50 \mathrm{~W}$ in the RTM. 

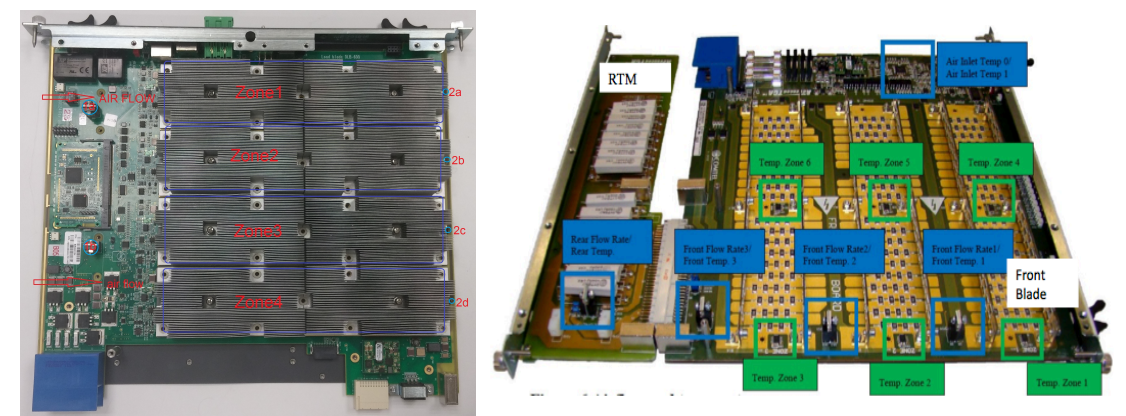

Figure 2: a) ASIS load boards, 10 embedded T sensors provide the thermal distribution. b) Comtel load blades, RTM side on the left part and the front blades is the right one.

\section{Vertical tests and results}

The tests were carried out at full power of the blades and with the top fans at the maximum speed. Figure 3a shows the distribution of temperature in 14 ASIS blades, installed in the bottom shelf. The blades are numbered starting from the centre of the crate, so that all the odd numbered blades are on the left and even numbered blades on the right. As can be observed the maximum target temperature of $50^{\circ} \mathrm{C}$ was exceeded by $1 \mathrm{~K}$ or $2 \mathrm{~K}$ on only a few occasions, except for one blade that reached $54{ }^{\circ} \mathrm{C}$.
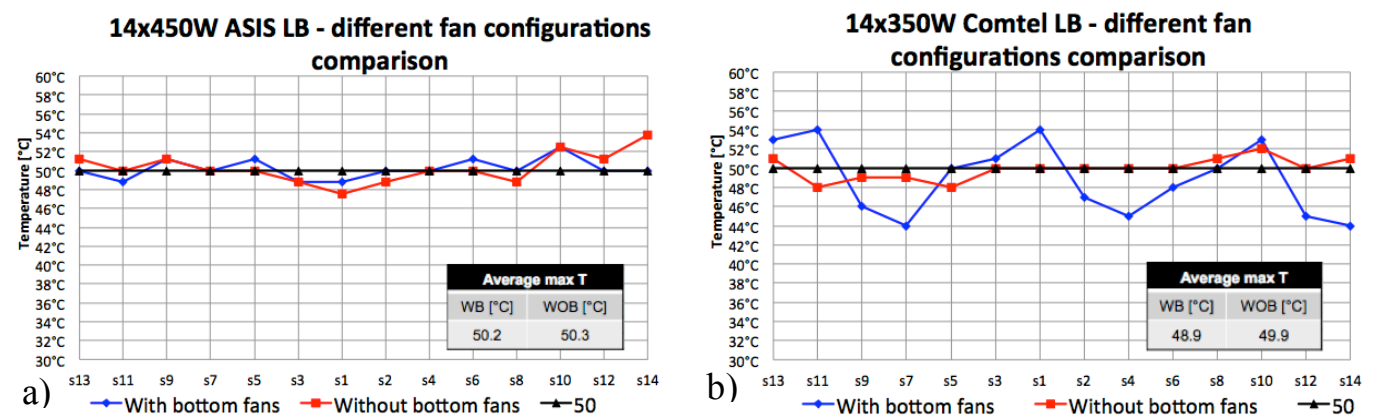

Figure 3: The impact of removing the bottom fan tray

(a) ASIS boards, (b) Comtel boards.

Comtel blades behaved differently, as can be seen in figure $3 \mathrm{~b}$. In this case the temperature distribution was less homogeneous with the bottom fan tray installed. Removing the fan tray increased the average temperature by $1 \mathrm{~K}$, but the maximum target temperature was not exceeded. The performance of the blades according to their position in the rack were measured and in general the bottom shelf is always slightly colder [6]. During the test campaign we also tested fan failures [6].

\section{Horizontal tests and results}

The temperature of the air released to the room is a critical parameter for the integration of the equipment into the ATLAS underground counting rooms (USA15), the present air conditioning system was not designed to manage high volume of air at high temperatures. The cooling door specifications were tested to verify that the air temperature released, in forced convection, was as cold as the room $\mathrm{T}\left(\approx 19^{\circ} \mathrm{C}\right)$. The tests were carried out with different water $\mathrm{T}$ and flow conditions.

With a water flow of $2.4 \mathrm{~m}^{3} / \mathrm{h}$ and $15^{\circ} \mathrm{C}$ inlet temperature, a $\Delta \mathrm{T}$ of $0.7 \mathrm{~K}$ on the average was measured between air inlet and outlet. When the water flow was increased to $3 \mathrm{~m}^{3} / \mathrm{h}$ the $\Delta \mathrm{T}$ 
became $0.4 \mathrm{~K}$. The air temperature released to the room decreased to about $21.5^{\circ} \mathrm{C}$ with an inlet water $\mathrm{T}$ of $13.5^{\circ} \mathrm{C}$, at this low water temperature, the dew point in the counting rooms could become an issue.

During the tests it was observed (Fig. 4) that the blades with higher air resistance showed better performance with both sets of the fans working (top and bottom). Comtel blades, with their lower air resistance, have a less homogeneous temperature distribution, which was also observed during the vertical tests.
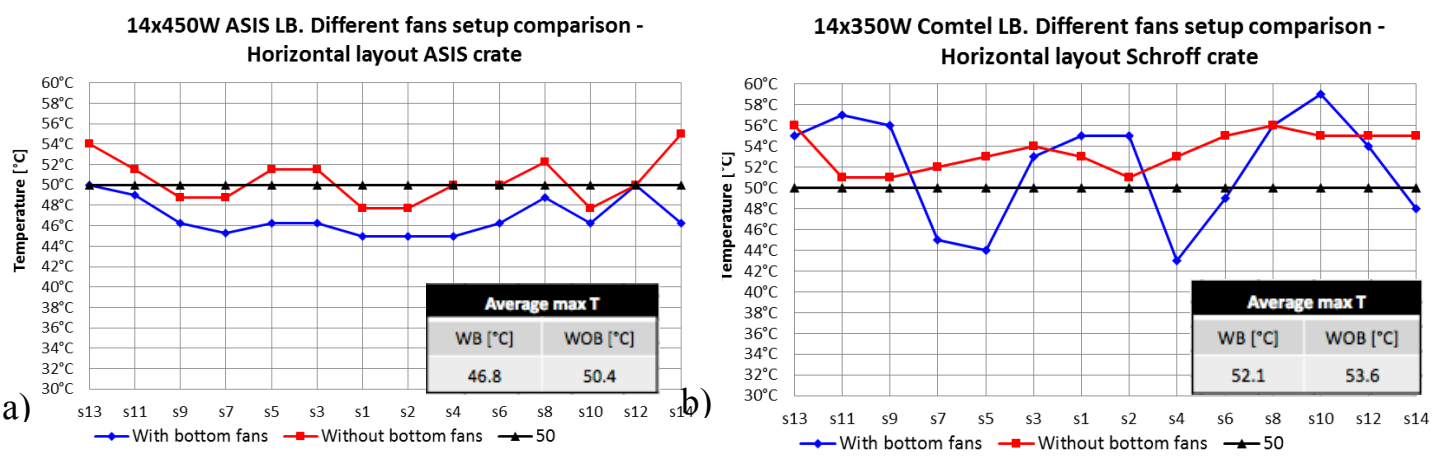

Figure 4: Different fans setting, temperatures on a) ASIS blades. b) Comtel blades.

There are many performing cooling doors available in the market and the horizontal layout is still a valuable commercial solution. But, the noise level with the horizontal layout would be higher due to the louder $16 \mathrm{U}$ shelves and the rack cooling doors. The actual vertical cooling architecture allows one to also have a smoke detection system monitoring per rack, which would not be easy to implement with the horizontal layout. A major consideration to keep in mind.

\section{Conclusions}

The performance of horizontal and vertical air cooling is not significantly different, but the existing infrastructure favors the vertical layout. A new rack concept would be required to fully harness the advantages of horizontal air cooling. But, extra warm air released rapidly into the counting room, could be an issue with horizontal cooling, unless a different cooling door is selected and a new smoke detection system is installed too. Currently a procurement framework for vertical ATCA shelves is being setup at CERN and solutions to reduce/confine the noise in the counting rooms are going to be implemented.

\section{References}

[1] M. Di Cosmo et al., Evaluation results of xTCA equipment for HEP experiments at CERN - TWEPP 2013 Perugia (Italy)

[2] ATCA evaluation project https://espace.cern.ch/ph-dep-ESE-BEATCAEvaluationProject/SitePages/Home.aspx

[3] http://www.itsirl.com/pt100theory.php

[4] ASIS ATCA Load Boards, http://www.asis-pro.com/atca-systems/600W-Load-Blade

[5] COMTEL ATCA Load Boards, http://www.comtel-online.com/index.php/products/atca/atca-testblades

[6] Full tests report: https://edms.cern.ch/document/1609794/1 